\title{
India Defeats Polio: Historical Health Milestone for Global Polio Eradication
}

\section{Mane Abhay B*}

Professor, Department of Community Medicine, Smt. Kashibai Navale Medical College, Pune, Maharashtra, India-411041

India has now been free of polio for more than 3 years and the South East Asian Region with 11 member states has begun the process of certifying polio-free status. This monumental task of interrupting the transmission of Wild Poliovirus (WPV) has been achieved in India. The last case of polio due to WPV was detected on 13 January 2011 in Howrah district of West Bengal [1]. Among developing countries, India was the worst affected with polio prior to its decline in the 1990s. The reported clinical poliomyelitis annually was more than 2 children among 1000 under-fives [2,3]. Thus polio was a huge problem based on humanitarian and economic reasons with an estimated total annual loss of 45 billion to the nation. This is in addition to the expenses incurred for travel and treatment, rehabilitation, calipers and wheel chair etc [4]. Hence India became a signatory to the World Health Assembly (WHA) resolution in 1988 to target polio for global eradication by 2000 in support of the decision [5]. World Health Organization (WHO) estimated that 150 countries had annual burden of 350,000 polio cases in 1988 [6]. This was a gross underestimate as India alone had 200,000 to 400,000 annual cases in mid-1980s [7]. Although the WHA decision to eradicate polio was taken in 1988 by India, the implementation started on a national level only in 1995-1996. In 1995 for India, the Global Polio Eradication Initiative (GPEI) spearheaded by WHO in partnership with UNICEF, Centers for Disease Control of USA and Rotary International designed National Polio Surveillance Project (NPSP), a joint project of the WHO and Government of India (GOI).

In 1994, a pilot polio immunization campaign was conducted in Delhi, targeting one million children up to $3 \mathrm{yr}$ of age. The Supplementary Immunization Activity (SIA) which was one of the strategies recommended by WHA was termed popularly as Pulse Polio Immunization (PPI) [8]. This pilot campaign was later expanded nationally in 1995 during which a total of 88 million under-3 children were immunized and the target age group was increased to all children under the age of $5 \mathrm{yr}$ from 1996. Active surveillance of acute flaccid paralysis (AFP) cases was undertaken in the entire country by NPSP in late 1997. By 1999, the India Expert Advisory Group for Polio (IEAG) was constituted by GOI to review progress and to modify tactics of SIAs for interrupting WPV transmission. Till 1999, PPI consisted of vaccination of children at fixed booths on two National Immunization Days (NIDs), separated by six weeks, during the winter months. After the nation-wide PPI campaigns from 1995 to 1999, WPV 2 stopped circulating by October 1999 because of sufficient level of coverage by trivalent OPV (tOPV) [9]. But the coverage was insufficient to interrupt WPV 1 and 3 transmissions. As a result, India missed the initial goal of reaching zero incidence of polio by 2000. During and since 2000, in addition to booth immunization, a house-to-house search of missed children and vaccinating them on the next 2-3 days following each national and sub-national PPI was adopted [10]. This was termed as Intensified PPI (IPPI). By 2000, there was a 99\% decline in polio cases from 1988. In 2000, NPSP adopted a 'virological scheme' of classification in place of 'clinical' classification of AFP cases. For this purpose, the WHO, in association with NPSP, strengthened several existing virology laboratories and networked them for virological surveillance of polio. Two consecutive-day stool samples were collected from each child with AFP and submitted to the designated laboratory under cold chain conditions. Each poliovirus isolate was analyzed to distinguish vaccine virus from WPV. Only if WPV was detected was the child diagnosed with polio. WPV circulation was limited essentially to the two northern States of UP and Bihar by 2001. Hence GOI declared 2005 as the target year in its National Health Policy for polio eradication. A major setback to the programme was in 2002, that saw an outbreak with 1,600 cases, nearly 87 per cent of cases detected globally, mostly of type 1 , and 1,363 (85\%) cases in UP and Bihar alone [11]. The failure to dislodge WPV 1 and 3 was attributed to inadequate numbers of annual PPI campaigns and also to their poor quality. In Uttar Pradesh (UP), an under-served strategy was introduced for better communication that aimed at engaging universities, religious leaders and groups, local associations and individuals from underserved Muslim communities to broaden ownership and accountability for polio eradication in 2003. Further improvement in poliovirus surveillance quality was seen in 2004 and the programme was able to rapidly detect poliovirus transmission anywhere in the country. To vaccinate the missed children due to migration, transit vaccination strategy was launched, with teams stationed at bus stands, railway stations, highways, markets and at congregation sites and provided polio vaccine to eligible children. Many children got polio in spite of seven or 10 or even 15 doses of tOPV. In 2005, monovalent OPV type 1 (mOPV-1) and type 3 (mOPV-3) were licensed based on an early Indian study showing 2.5 to 3 times higher vaccine efficacy of mOPV-1 and $\mathrm{mOPV}-3$ than that of tOPV $[12,13]$. Due to inadequate coverage of under-five children in UP and Bihar with OPV doses, both under routine EPI schedule and in PPI, there was a polio outbreak in 2006, with 648 cases of type 1 and 28 of type 3 [14]. Hence the PPI campaigns were increased to 10 per year, and neonates and very young infants were specially targeted. NPSP continued with multiple campaigns using mOPV-1 in UP and Bihar. This was also based on recommendations of the Global Advisory Committee on Polio Eradication and IEAG, India prioritized elimination of WPV1 from 2006/2007 because it was the most frequent cause of paralytic disease, was responsible for $>90$ per cent of polio cases in the country during the previous five years. Finally its transmission ceased in January 2011. This strategy failed to prevent outbreaks of WPV 3 in UP and Bihar in 2007-2009 [15]. The WPV-3 outbreaks during 2007-2009 were seen as failure by some experts while the concurrent elimination of WPV-1 in UP and Bihar was lauded as success by others. In November 2009, the IEAG

*Corresponding author: Dr. Mane Abhay B, Department of Community Medicine, Smt. Kashibai Navale Medical College, Narhe, Pune, Maharashtra, India, Tel: 8975008663; E-mail: drabmane@yahoo.co.in

Received January 19, 2014; Accepted January 30, 2014; Published Feburary 08, 2014

Citation: Mane Abhay B (2014) India Defeats Polio: Historical Health Milestone for Global Polio Eradication. Primary Health Care 4: e109. doi:10.4172/21671079.1000e109

Copyright: ( 2014 Mane Abhay B. This is an open-access article distributed under the terms of the Creative Commons Attribution License, which permits unrestricted use, distribution, and reproduction in any medium, provided the original author and source are credited. 
Citation: Mane Abhay B (2014) India Defeats Polio: Historical Health Milestone for Global Polio Eradication. Primary Health Care 4: e109. doi:10.4172/2167-1079.1000e109

declared that 107 blocks in western UP and central Bihar were holding the key to eradication in India. In 2009, the IEAG recommended the use of bivalent OPV containing types 1 and 3 (bOPV) instead of mOPV-3 to address both WPV-1 and 3 [16]. But IEAG guided the battle against polio with continued vigour that resulted in detection of only $42 \mathrm{WPV}$ cases in 2010. This emboldened the GOI to recommend responding to each case of polio as a public health emergency. The introduction of bOPV in SIAs beginning in January 2010 contributed substantially to the sustainment of simultaneous reduction in WPV1 and WPV3 cases. Finally, there was only one case in January 2011 (Figure 1). Subsequently, India was removed from the list of polio endemic countries after completing a year without reporting any more WPV isolate from case or environmental samples. The SEA Regional Certification Committee will review all information and will consider certification since its three consecutive years from the last WPV isolate in the region. The programme developed need-based strategies for reaching maximum children during each PPI campaign that involved nearly 170 million children in more than 240 million households by 2.3 million vaccinators [17]. The programme overcame some of the challenges and hurdles like-

1. Vast and dense population with diverse socio-cultural practices

2. Physical and social barriers

3. Low routine vaccination coverage

4. Vulnerable and migrant population

5. Weaknesses in health systems

6. Social resistance to vaccination

7. Fatigue and fear of adverse events following immunization by parents

India's achievement is proof of what is possible when the global community comes together in support of polio eradication. Long recognized as one of the most difficult places to eradicate polio, India

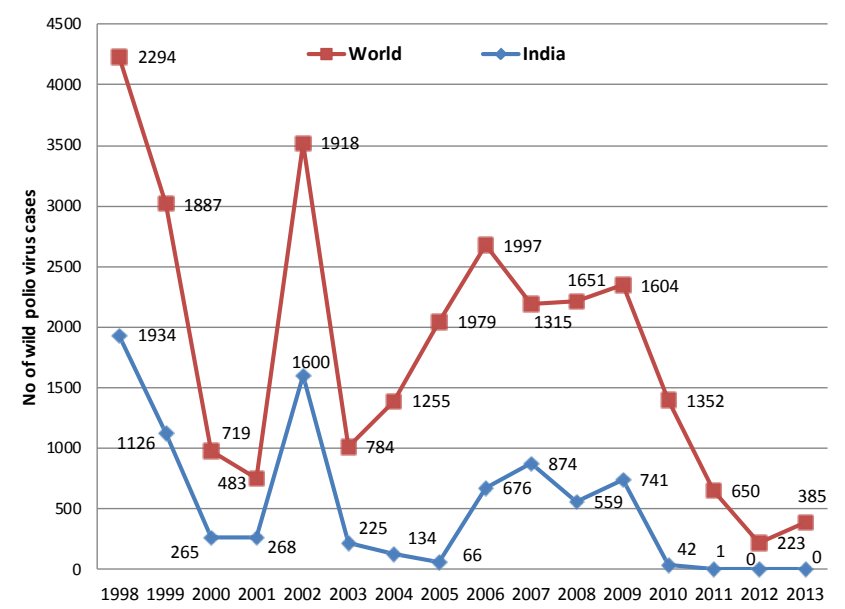

Figure 1: Worldwide trend of wild polio cases compared with India. now stands as an example for how to mount a successful disease response effort under the most complex circumstances. Research and innovations have been an integral part of the programme that provided new directions to the eradication effort.

India has to announce the steps to complete and conclude polio eradication, as per the WHO "polio eradication end game strategy". The journey of India towards polio eradication was extremely difficult in the last two decades. It has taught several lessons and may be helpful for devising strategies in eradication of other diseases in future. The elimination of WPVs stands as an eloquent testimony to the effective leadership of NPSP, the close cooperation by the GOI and State Governments and the sincere work of countless health-workers, nongovernmental organizations (NGOs), and local volunteers. The polio eradication programme will be a 'model of excellence' for other public health initiatives in India and across the globe.

\section{References}

1. http://www.searo.who.int/india/topics/poliomyelitis/polio_eradication/en/index html.

2. Prabakar N, Srilatha V, Mukerji D, John A, Rajarathnam A, et al. (1981) The epidemiology and prevention of poliomyelitis in a rural community in south India. Indian Pediatr 18: 527-537.

3. Srilatha V, Mukarji D, John TJ (1984) The prevalence of poliomyelitis in rura school children in South India. J Trop Pediatr 30: 68-69.

4. John TJ (1981) Cost and benefits of immunization in India. Indian Pediatr 18 513-516.

5. World Health Assembly (1988) Global eradication of poliomyelitis by the year 2000. Forty-first World Health Assembly, Geneva, May 2-13. Resolution 41.28.

6. http://www.polioeradication.org/Polioandprevention/Historyofpolio.aspx.

7. Andrus JK, Banerjee K, Hull BP, Smith JC, Mochny I (1997) Polio eradication in the World Health Organization South-East Asia Region by the year 2000 midway assessment of progress and future challenges. J Infect Dis 175 Suppl 1: S89-96.

8. John TJ, Pandian R, Gadomski A, Steinhoff M, John M, et al. (1983) Control of poliomyelitis by pulse immunisation in Vellore, India. Br Med J (Clin Res Ed) 286: 31-32.

9. Centers for Disease Control and Prevention (CDC) (2001) Apparent globa interruption of wild poliovirus type 2 transmission. MMWR Morb Mortal Wkly Rep 50: 222-224.

10. Centers for Disease Control and Prevention (CDC) (2004) Progress toward poliomyelitis eradication--India, 2003. MMWR Morb Mortal Wkly Rep 53: 238241.

11. http://www.cdc.gov/mmwr/preview/mmwrhtml/mm5216a4.html.

12. John TJ, Devarajan LV, Balasubramanyan A (1976) Immunization in India with trivalent and monovalent oral poliovirus vaccines of enhanced potency. Bull World Health Organ 54: 115-117.

13. Grassly NC, Wenger J, Durrani S, Bahl S, Deshpande JM, et al. (2007) Protective efficacy of a monovalent oral type 1 poliovirus vaccine: a casecontrol study. Lancet 369: 1356-1362.

14. Roberts L (2006) Infectious disease. Polio experts strive to understand a puzzling outbreak. Science 312: 1581

15. Centers for Disease Control and Prevention (CDC) (2009) Progress toward poliomyelitis eradication--India, January 2007-May 2009. MMWR Morb Mortal Wkly Rep 58: 719-723.

16. Sutter RW, John TJ, Jain H, Agarkhedkar S, Ramanan PV, et al. (2010) Immunogenicity of bivalent types 1 and 3 oral poliovirus vaccine: a randomised double-blind, controlled trial. Lancet 376: 1682-1688.

17. http://www.livemint.com/Opinion/JD8uPXvircS0rU60AIUvUN/Polioeradicationa-landmark-achievement-for-India.html. 